\title{
PAPEL DA ENFERMEIRA NA AQUISIÇÃO DE MATERIAL TÉCNICO
}

\section{Victória Secaf *}

RBEn/07

SECAF, V. - Papel da enfermeira na aquisição de material técnico. Rev. Bras. Enf.; DF, $28: 69-79,1976$.

\section{INTRODUÇĀO}

Em função do próprio exercício profissional a enfermeira está diretamente ligada ao processo de aquisição de material técnico, material este que ela requisita, recebe, prepara, utiliza e controla.

Como elemento técnico da Comissão de Compras ou como enfermeira de uma Unidade Médico-Assistencial, ela deve estar consciente da importância de sua colaboração e atuar devidamente pois participa do processo de aquisição, ainda que não haja nos Manuais de Material ou Serviço de Compras, qualquer referência à sua atuação.

Se examinarmos o sistema de compras de um serviço de saúde veremos que o início é dado pela enfermeira, quando faz a identificação da maioria de materiais necessários à sua unidade de trabalho. E, se examinarmos o final do processo veremos que a experimentação e o uso do material adquirido pelos serviços de saúde são determinados também pela enfermeira.
Na aquisição de materiais de outras áreas, como lavanderia e nutrição, por exemplo ela também participa, tendo em vista a utilização comum dos equipamentos e o entrosamento entre aqueles serviços e o de enfermagem.

Nossa experiência, em São Paulo, como membro de Comissōes de Material Técnico Permanente e de Consumo, é satisfatória e permite esclarecer alguns aspectos e proporcionar subsídios, quanto a aquisição de material técnico, às enfermeiras, de um modo geral e para aquelas em idêntica situação à nossa.

\section{O MATERIAL NO SERVIÇO PÚBLICO}

Em administração, o fator "material" é tão importante quanto "pessoal" e "dinheiro" e nenhum serviço pode desempenhar suas funçōes sem estar devidamente equipado.

O problema, em seu conjunto, deve convergir para o tipo de material que a instituição pública utiliza, sua quantidade, como e onde é empregado.

* Enfermeira do INPS/Såo Paulo. Docente da EEUSP/SP. 
SECAF, V. - Papel da enfermeira na aquisiçāo de material técnico. Rev. Bras. Ene.; DF, $28: 69-79,1976$.

As entidades governamentais adquirem todo tipo de material e em todas as quantidades, para os mais diversos Serviços, variando desde um navio até alfinetes ou mesmo miligramas de um produto químico.

Como nosso enfoque é material técnico-hospitalar poderiamos citar desde a compra de monitores e mesas cirúrg1cas até agulhas hipodérmicas ou simples termômetros clínicos.

A Administração Pública, através de suas entidades estatais e autárquicas, faz compras, realiza obras e serviços e aliena bens. Estas atividades são executadas através de contratos que dependem de um procedimento seletivo prévio denominado LICITAÇÃO.

Pelo Decreto-lei 200/67(1), a sistemática da licitação foi atualizada e simplificada e por norma subseqüente foi feita aplicação dos preceitos legais quanto à licitação federal aos Estados e Municípios e a regulamentação supletiva face às peculiaridades regionais e locais.

Com a legislação especifica, nas três esferas estatais e suas autarquias, pode-se informar que a Administração Pública Brasileira possui um sistema uniforme de licitação, respeitadas as características próprias estaduais e municipais.

Assim sendo, para este trabalho, com base na experiência em Comissōes de Compras, vamos nos referir a normas, rotinas e exemplos de aquisição de material técnico, no Instituto Nacional de Previdência Social (INPS), certas de que poderão ser aplicáveis a outras entida- des governamentais e, adaptada a situaçōes, em hospitais particulares, sujeitos como empresas a regimentos especificos.

Segundo Lopes Meirelles, (2) "LICITAÇOES" é o procedimento administrativo mediante o qual a Administração Pública seleciona a proposta mais vantajosa para o contrato do seu interesse.

O procedimento da licitação tem fases e atos específicos, está sujeito a determinados principios e a três modalidades: concorrência, tomada de preços e convite.

CONCORRENCIA é a modalidade de licitação a que deverá recorrer a Administração nos casos de compras, obras ou serviços de vulto, em que se admite a participação de qualquer licitante através de convocação da maior amplitude ( $\S 1 .^{\circ}$ do art. 127 do Decreto-lei 200/67).

TOMADA DE PREÇOS é a modalidade de licitação entre interessados previaviamente registrados, observada a necessária habilitação ( $\S 30^{\circ}$ do art. 127 do Decreto-lei 200/67).

CONVITE é a modalidade de licitação entre interssados no ramo pertinente ao objeto da licitação em número mínimo ce 3 (três), escolhidos pela unidade administrativa, registrados ou não, e convocados por escrito com antecedência minima de 3 (três) dias úteis ( $\S 4 .^{\circ}$ do art. 127 do Decreto-lel 200/67).

A modalidade de licitação a ser adotada é estabelecida pelo valor estimativo da despesa ( $85^{\circ}$ do art. 127 do Decreto-lei 200/67).

(1) Decreto-lei 200 de 25 de fovereiro de 1967 - Di־Dõe sobre a organização da Administraçāo Federal, estabelece diretrizes para a reforma Administrativa e dá outras providências. Título XII - Das normas relativas a licitaçōes para compras, obras, serviços e alienaçōes. Arts. 125 a 144. 
SECAF, V. - Papel da enfermeira na aquisiçåo de material técnico. Rev. Bras. Enf.; DF, $28: 69-79,1976$.

Toda licitação terá por objeto uma obra, um serviço, uma compra, uma alienação, uma locação ou uma concessão.

A contribuição da enfermeira, pelo seu parecer técnico, poderá ser solicitada para qualquer destes objetos de licitaçāo, porém, neste trabalho, o enfoque será compra de material médico hospitalar ambulatorial.

Como objeto de licitação, COMPRA "é um contrato pelo qual um dos contraentes se obriga a transferir o dominio de certa coisa e o outro, a pagarlhe certo preço em dinheiro". (9)

Na licitação para compra, a Administração deve especificar o objeto a ser adquirido, quantidade do mesmo, condições em que deseja adquirir e outras indicações como veremos adiante.

As ESPECIFICAÇOES de material, são "declaraçōes formuladas, definidas e completas do que o comprador exige do vendedor". (14)

A especificação nāo é apenas a descrição de padrōes; ela deve conter o que deverá ser fornecido pelo vendedor quanto à composição, construção, utilldade, durabilidade, eficiência, textura, forma ou dimensão.

Neste trabalho vamos nos referir a material, permanente ou de consumo e serão focalizados apenas os aspectos gerais da aquisição, seguidos pelo INPS, através de Instrução de Serviço. (7)

No INPS, através de Orientação de Serviço (5) os materiais adquiridos para uso nos diversos setores são considerados como:

- bens móveis: (Equipamento e Ins- talaçōes e Material Permanente) quando tiverem duraçāo superior a 2 anos e forem inconsumíveis pelo próprio uso.

- materiais de consumo: quando a duração nāo ultrapassar dois anos, forem consumíveis pelo próprio uso ou se destinarem a substituição de peças sobressalentes ou acessórios.

\section{PROCESSAMENTO DE COMPRAS}

No Instituto Nacional de Previdência Social (INPS), a aquisição de equipamento permanente é feita nas Superintendências Regionais, pelo Serviço de Material, da Sub-Secretaria de Serviços Gerais e do Patrimônio (Anexo I) através de licitaçōes, (art. 126 do Decreto-lei 200/67) com base nos dispositivos de Orientação de Serviço (6).

A aquisição de material técnico por importação direta é realizada por Departamento próprio da Direção Geral *, e a legislação, mais atual e especifica, para compra de material importado apresenta, no momento, severas restriçōes do Governo, quanto a esse tipo de compras.

As aquisições de material médico-hospitalar de consumo são realizadas pelas Superintendências, exceto para os hospitais que 0 adquirem através de licitações nos próprios locals.

A legislação especifica estabelece que, entre outros, é dispensível a lícitação: "nos casos de emergência, caracterizada a urgência de atendimento de situação que possa ocasionar prejuízos ou comprometer a segurança de pessoas, bens ou equipamentos".

Este procedimento está sujeito à ho-

* o órgão central e a ele cabe orientar e supervisionar as atividades de material nas Buperintendências Regionais. 
SECAF, V. - Papel da enfermeira na aquisição de material técnico. Rev. Bras. Enf.; DF, 28 : 69-79, 1976.

mologação de autoridade superior àquela que aprovou a compra.

Para exemplificar, lembramos que, com o surto de meningite ocorrido em São Paulo, em 1974, foram efetuadas compras sem licitação de determinados materiais, necessários ao hospital do INPS que atendia portadores desta moléstia. Além disso, os hospitais e postos de assistência podem adquirir materiais de consumo com dispensa de licitação, sem ultrapassar determinados valores e de acordo com circunstâncias especiais, quais sejam: quando o material não pertencer à linha normal de consumo ou que não tenha sido fornecido pelo setor de Abastecimento.

Os Serviços das Unidades Médico-Ássistenciais (Hospitais e Postos de Assistência) inclusive o de Enfermagem após o levantamento das necessidades de material, fazem os pedidos. Cabe às enfermeiras dos Serviços fornecer os dados quanto à especificação técnica de cada material: requisições completas e com especificação correta fornecem dados para que as Comissões de Compras funcionem melhor e mais rapidamente.

Em prazo previamente determinado, o Setor de Material das Unidades reúne e codifica os pedidos dos vários Serviços, os quais são analisados para aprovação pela Chefia da Unidade MédicoAssistencial.

O sistema de classificação e codificação de material é padronizado nas entidades apresentando variações nos órgãos federais, estaduais ou municipais. No INPS, através de Orientação de Serviço, consta que os materiais obedecerão à nomenclatura, classificação e codificação já estabelecidos, os quais serāo observados em todos os documentos especificos de material, inclusive no Caderno de Material.
O Setor de Material de cada Unidade, elabora a Previsão Orçamentária de Bens Móveis (POB) que são enviadas e reunidas pelo Serviço de Material Regional e criticadas pela Sub-Secretaria de Assistência Médica.

A seguir, o Serviço de Material Regional analisa a POB, atribui estimativa de custo, totalizando quantidades $e$ valores, observadas as classificações contábeis e elobaram a POB geral que é enviada para ser submetida à crítica da Direção Geral.

O Serviço de Material Regional remete a POB aprovada às Unidades MédicoAssistenciais para adequação às dotações disponíveis.

O Setor de Material das Unidades Médico-Assistenciais, após adequação às dotações orçamentárias disponíveis, emite as Requisições de Material (RM), para aqueles materiais considerados prioritários.

O Serviço de Material Regional confere e reúne as RM, elaborando o Plano de Aquisição de Bens Móveis (PABM).

Este é recebido para aprovação pelo órgão Central de Material e são liberadas as dotações orçamentárias para as aquisições.

O Serviço de Material Regional submete o PABM aprovado à Comissão Técnica que analisa e complementa tecnicamente cada especificação para abertura das licitações. O Serviço de Material Regional providencia a emissão do Pedido de Compra de Material (PCM) conforme a especificação e de acordo com a dotação Orçamentária, e' isto vai constituir o elemento fundamental de todo o processo.

A emissão do PCM visa o atendimento da requísiçāo dos serviços ou manu- 
SECAF, V. - Papel da enfermeira na aquisiçāo de material técnico. Rev. Bras. Enf.; DF, 28 : 69-79, 1976.

tenção do estoque quando se tratar de material de consumo.

A Comissão Técnica, de posse do mapa resumo das propostas e amostras enviadas pelas firmas, analisa as ofertas e emite parecer técnico.

A norma federal das licitaçōes (art. 133 do Decreto-lei 200/67) declara que, na fixação dos critérios de julgamento das propostas deve-se levar em conta, no interesse do Serviço Público, os fatores de qualidade, rendimento, preço, condiçōes de pagamento e outras pertinentes, estabelecidas no Edital.*

Cabe à enfermeira, entre os demais elementos técnicos, baseados em critérios objetivos e impessoais, escolher o material que melhor atenda ao interesse do serviço.

Como nem sempre o material escolhido é o de menor preço, o elemento técnico deverá justificar, por escrito, as razōes da escolha pela qualidade, conforme estabelece a legislação que serve de base para as Orientaçōes do INPS nesse sentido.

Dizemos que a escolha de um determinado material foi feita pela qualidade quando está apto a satisfazer o fím a que se destina. Deve-se julgar também pelo fator rendimento, que é, em última análise, a utilidade do objeto licitado.

Cada aparelho ou instrumento vai ser selecionado pela potência, manutençāo, eficiência, fatores estes que vão influir na produtividade do material.
Quando o material é de consumo e sujeito a possíveis variaçōes de qualidade, como por exemplo: luvas cirúrgicas, deverá ser exigido pela enfermeira, membro da Comissão, uma quantidade maior do número de amostras para que o material seja testado e confrontado com as várias marcas.

O resultado dos testes, efetuados por enfermeiras de várias Unidades Assistenciais, deverá ser exigido, por escrito, documentado e deverá conter as caracteristicas verificadas de qualidade, perfeição e durabilidade de material.

O Serviço de Material Regional relata o processo para a aprovação da autoridade competente, expedindo Ordem de Fornecimento (OF).

O material recebido deverá ser aceito do ponto de vista técnico antes de ser incorporado ao acervo da Instituição.

O material aceito é fornecido pelo Serviço de Material regional aos setores de Material das unidades que os redistribuem aos respectivos Serviços e Clínicas especializadas para utilizaçāo.

As caracteristicas administrativas do processamento de licitaçōes para material de consumo são similares ao material permanente exceto pelo fato de que se repetem várias vezes ao ano dependendo das previsōes e utilização.

Neste esboço tentamos mostrar a seqüência de aquisição de material desde sua requisição até o recebimento do mesmo conforme pode ser observado no fluxograma abaixo.

- Edital é o instrumento através do qual a Administraçāo leva ao conhecimento público a ubertura da concorrência ou a tomada de preços, fixa as condiçóes de sua realizaçāo e convoca os interessados para a apresentação de suas propostas. 
SECAF, V. - Papel da enfermeira na aquisição de material técnico. Rev. Bras Ene; DF, 28 : 69-79, 1976.

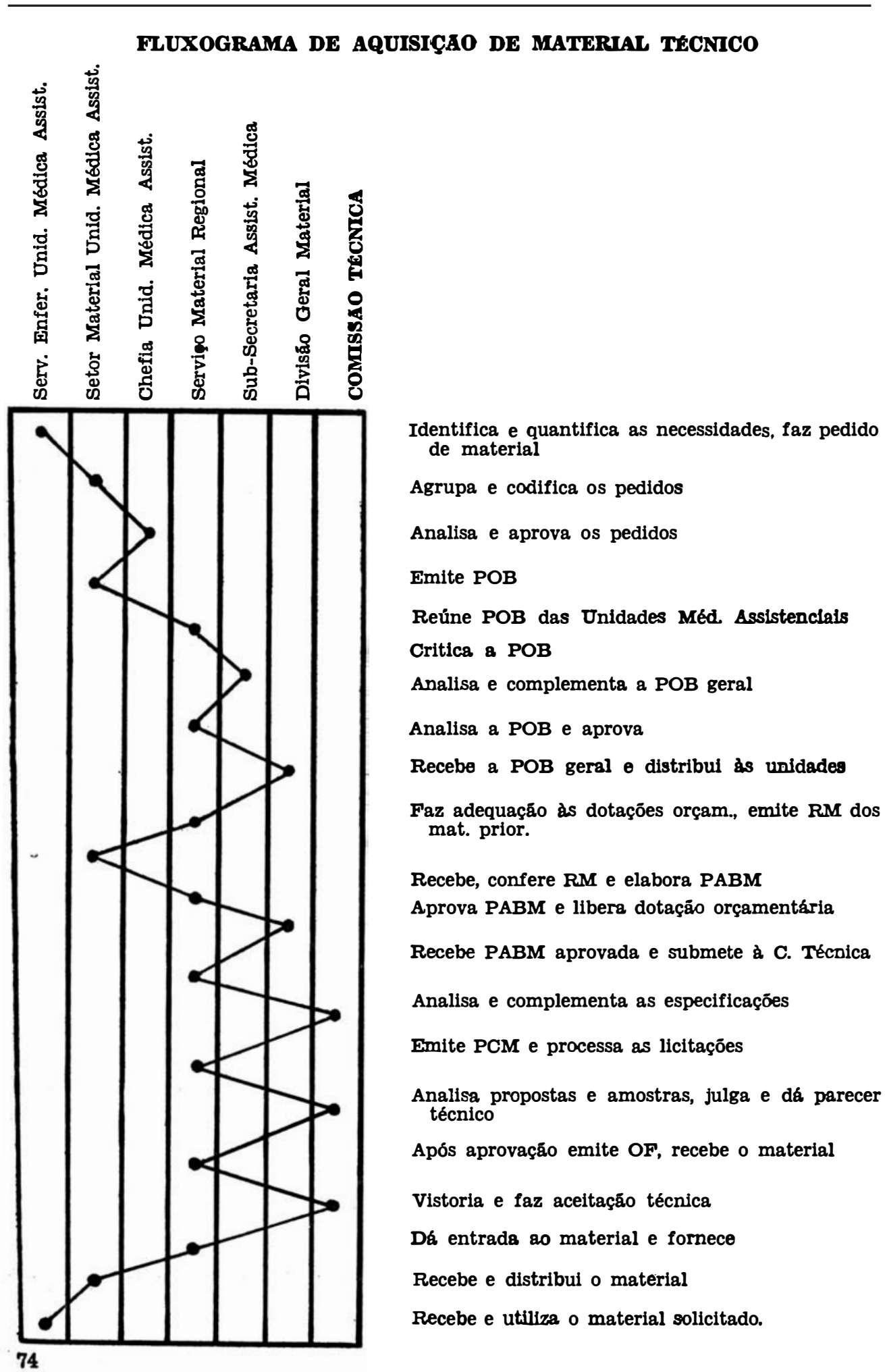


SECAF, V. - Papel da enfermeira na aquisição de material técnico. Rev. Bras. Ene.; DF, $28: 69-79,1976$.

\section{ATUAÇĀO DA ENEERMEIRA}

As enfermeiras das unidades médicoassistenciais conhecem o suficiente sobre o processamento de compras de material que solicitam? Elas valorizam a importância de sua atuação ao elaborar cada requisição do seu setor? Estas perguntas merecem reflexão e fazem parte dos motivos que nos levaram a redigir este trabalho.

A enfermeira-chefe de uma instituição ou de um de seus setores deve aplicar no seu trabalho, quanto ao material, alguma das funçōes de administração: prever, organizar, controlar. Deve manter atualizada sua relação das necessidades de material, permanente e de consumo, e das futuras solicitaçōes a serem feitas. Deve identificar e quantificar os materiais e, para os de consumo, basear-se no gasto médio mensal.

fundamental para o andamento do serviço que a enfermeira requisite os materiais necessários, em tempo hábil e não ocorra que seja colhida de surpresa pelo fato de que a chefia pede geralmente, em prazos muito curtos, a relação do material a ser requisitado.

As requisiçōes, por ela feitas, deverão ser fruto da análise do material a ser solicitado e assim incluir o maior número possível de esclarecimentos sobre o mesmo.

O INPS, através de Orientação de Serviço, baseado no Decreto-lei 200/67 estabelece que, se houver exigência da marca do material é imprescindível que haja uma convincente Justificativa técnica para os mesmos. Caberá à profissional elaborar essa justificativa.

Sugerimos pois a cada enfermeira que:

a) mantenha atualizada sua relação de material a ser solicitado;

b) faça consultas freqüentes ao caderno de material de sua Instituição;

c) elabore requisiçōes completas, esclarecedoras e codificadas corretamente; d) acrescente Justificativas convincentes quando houver exigência de uma determinada marca de material;

e) procure conhecer as inovaçōes de material e produtos novos que possam ser necessários ao trabalho nas unidades Médico-Assistenciais;

f) participe na execução de testes de material de consumo, quando solicitada;

g) comunique, por escrito, qualquer restrição ao material recebido para que o fato seja levado em consideração ao serem efetuadas novas compras daquele material.

de supor que, nesta era tecnológica que atravessamos, as enfermeiras com seu preparo específico de administração tenham vivência sobre processamento de compras e sejam supérfluas as sugestōes acima.

Sobre a atuação da enfermeira em Comissōes de Compra de Material Técnico é patente que a profissional pelo seu preparo não só está capacitada como a ela cabe "emitir parecer" pois esta é uma atividade inerente à sua função e está prevista na descrição de tarefas da Classificação Brasileira de Ocupaçōes (Departamento Nacional de Mão de Obra).

A enfermeira, como elemento técnico, deve participar em todas as fases de aquisição de material: especificação, julgamento e aceitação do material.

Na 1." fase, ou seja de especificação, à enfermeira solicitada para membro técnico de Comissōes de Compras, caberia:

A) Análise cuidadosa das requisiçōes recebidas dos vários setores de hopitais e ambulatórios.

Esta análise incluiria não só a aplicabilidade e utilidade do material solicitado para aquele setor, como também observação quanto a quantidade do mesmo.

B) Estudo das necessida.des de material dos setores e, quando a Previsão Orçamentária de Bens Móveis (POB) não 
SECAF, V. - Papel da enfermeira na aquisição de material técnico. Rev. Bras. Enf.; DF, $28: 69-79,1976$.

for suficiente para a totalidade das requisiçōes, estabelecer critérios para os possiveis cortes de pedidos não prioritários. sabido a existência de setores que dispōem de aparelhagem, de preço elevado, armazenada sem uso, porque o material não corresponde ao especificado ou não houve uma triagem das reais necessidades.

C) Após a aprovação da POB, análise da redação de cada especificaçāo enviada pelos setores.

Como dissemos, o elemento principal do mecanismo da compra é a especificação e padronização do material. A elaboraçāo de especificaçōes claramente definidas constitui uma tarefa técnica e a enfermeira deve estar consciente do valor que isto representa.

O conteúdo de uma especifícação vaí variar dependendo do material, porém há "regras" que poderiam ser seguidas. No exemplo abaixo observa-se a seguinte seqüência: - nome do material

- sua destinação

- título, se houver

- características como: tipo, formato, tamanho, material que é fabricado

- número e nome do catálogo de referência

- referência ao similar

"Pinça para cirurgia geral, de Kelly. hemostática, reta, de 14 centímetros aproximadamente, aço inox, tipo tal, catálogo X ou similar".

Para o equipamento elétrico não deve ser esquecida a voltagem e ciclagem e se está de acordo com a cidade a que se destina.

Para material de grande porte é necessário determinar a área livre para a sua instalação e aspectos necessários para seu funcionamento como: instalação de água, luz e esgoto, para uma autoclave.

Quando o material é pintado ou de fórmica deve ser referido o nome, número e tipo da cor escolhida dentre os catálogos mais conhecidos, existentes no comércio.

Para determinados equipamentos devem ser incluídos exigências como: instalação no local, orientação aos funcionários sobre o funcionamento, atestado de garantia e assistência técnica permanente.

Na fase de julgamento, cabe à enfermeira após a análise do mapa de propcstas dos fornecedores, fazer a leitura detalhada da especificação do material oferecido por cada um deles. A isto deve seguir o confronto do oferecido com a especificação constante no Edital.

Esta comparação permitirá a exclusão do material de vários fornecedores por nāo corresponderem às especificaçōes exigidas.

Para aqueles materiais em que foi encontrada uma perfeita identificação entre o requisitado e o oferecido, a enfermeira deverá examinar a amostra apresentada, quando necessário. Para material de consumo, a amostra é indispensável e para muitos deles devem ser realizados testes. Além disso, para aqueles materiais que exijam segurança para o paciente quanto às condiçōes de fabricaçāo e esterilizaçāo, seria aconselhável, antes do parecer técnico, uma visita de vistoria às fábricas pelos membros da comissão. Exemplos desses materiais: fios cirúrgicos, soro, equipos, seringas e agulhas descartáveis.

Para determinados materiais, como mesas cirúrgicas, autoclaves, máquinas de lavar luvas, seria aconselhável uma visita às instituiçōes de saúde que tenham esses materiais em uso.

Após estes cuidados, de acordo com o critério de preços, prazo e qualidade será elaborado o parecer técnico visando a aquisição do material que melhor atenda ao interesse do serviço.

O êxito das compras depende da capacidade técnica, da integridade e do senso de trabalho de equipe das pessoas que constituem a comissão. 
SECAF, V. - Papel da enfermeira na aquisição de material técnico. Rev. Bras. Enf.; DF, 28 : 69-79, 1976.

E necessário que o parecer técnico pretenda obter "o material certo, no tempo certo e ao preço certo". Isto resulta de um esforço sistemático que exige conhecimento específico de material (característica essencial para uma enfermeira de comissão) e qualidades outras que poderão ser adquiridas e desenvolvidas.

$\mathrm{Na}$ fase de recebimento das compras a enfermeira da Comissão fará a aceitação técnica para quase a totalidade do material, exceto aqueles muito espe-. cializados em que recorrerá ao especialista.

\section{CONSIDERAÇŌES FINAIS}

Como para os hospitais e ambulatórios a meta é sempre renovar e atualizar o equipamento e, como consta da legislação a necessidade de parecer técnico nas licitaçōes, é certo que novas enfermeiras dos serviços públicos sejam solicitadas para a Comissão de Compras, além daquelas que já estão atuando.
O preparo específico e as vivências anteriores de cada enfermeira devem servir de base para a escolha de elementos para esta atividade, porém não devem ser esquecidas determinadas características de personalidade como bom senso, iniciativa, honestidade profissional e atitudes coerentes. Deverá demonstrar maturidade no relacionamento com outros funcionários e elementos de firmas e ainda procurar documentar e estabelecer dados estatísticos de todas as suas atividades, complementando seu trabalho na Comissão, periodicamente, com um relatório fiel, completo e com as sugestōes que se fizerem necessárias.

nosso desejo que, através deste trabalho, as enfermeiras que atuam em Comissōes de Compras procurem, por entrosamentos periódicos e reuniōes, proporcionar a troca de experiência para o maior desenvolvimento profissional de todas as enfermeiras, em suas atividades no processamento de compras.

\section{BIBLIOGRAFIA}

1. BARBEIRO, N. - A compra nos hospitais governamentais. Rev. Paul Hosp., 10 (4): 12-16, abr., 1962.

2. BONILHA, M.H.A. - O serviço de compras no hospital. Rev. Paul. Hosp., 15 (11): 16-22, nov., 1967.

3. CAVALCANTI, T.B. - Teoria dos atos administrativos. São Paulo, Revista dos Tribunais, 1973.

4. GAROFALO, F. - Aquisição de mateterial para o hospital. (In: Associaçāo dos Hospitais do Rio de Janeiro - Primeira Jornada de Administração Hospitalar. 14-21 novembro, Rio de Janeiro, p. 16579, 1959.

5. INSTITUTO NACIONAL DE PREVIDENCIA SOCIAL - Orientaçāo de Serviço n. ${ }^{\circ}$ SAP $604.6-17$ Jul., 1968. Abastecimento, Movi- mentaçåo, Registro e Controle de Material, serviços e obras. BS/ INPS, 143 26-7, 1968.

6. viço n. ${ }^{\circ}$ SAP 604.9 - 22 ago., 1969. Compra de Material e contrataçno de obras e serviços. BS/INPS, 174-11 de 1969

7. - Instruçāo de Serviço. SAM 399.6 - 27 de março 1966. Oniformiza o processamento de requisição de material especializado destinado a Serviços médicos, odontológicos e farmacêuticos. BS /INPS, 64 de 7-4-1969.

8. JAMESON, S.H. - Administração de material. 2. ed., Rio de Janeiro, Ed. Fundaçāo Getúlio Vargas, 1963 (textos selecionados de administração pública, 11). 
SECAF, v. - Papel da enfermeira na aquisição de material técníco. Rev. Bras. En?.; DF, 28 : 69-79, 1976.

9. MEIRELLSS, H.L. - Licitaçāo e contrato administrativo. Sāo Paulo, Ed. Revista dos Tribunais, 1973.

10. MELLONI, L. - Serviço de material para um hospital geral. Rev. Paul. Hosp., 1 (8): 27-311, ago., 1953.

11. MTSSIAS, S.B. - Especificação, normalização e padronização de material In: Manual de administracáo de materiais: normas, métodos e organizaçāo. 2. ed., São Paulo, Atlas, 1972, p. 28-36.
12. MONTHIRO, F., A.J. - Servico de material. Rev. Paul. Hosp., 16 (11) : 42-4, nov., 1966.

13. REIS, S.B. - Serviço de material no hospital. Rev. Paul. Hosp., 11 (2): 3-12, fev., 1963.

14. RIBEIRO, O.C. - Padronização. In: JAMESON, S.H. - Administras5o de material. 2. ed., Rio de Janeiro, Fundação Getúlio Vargas, p. 139-155, 1963. 


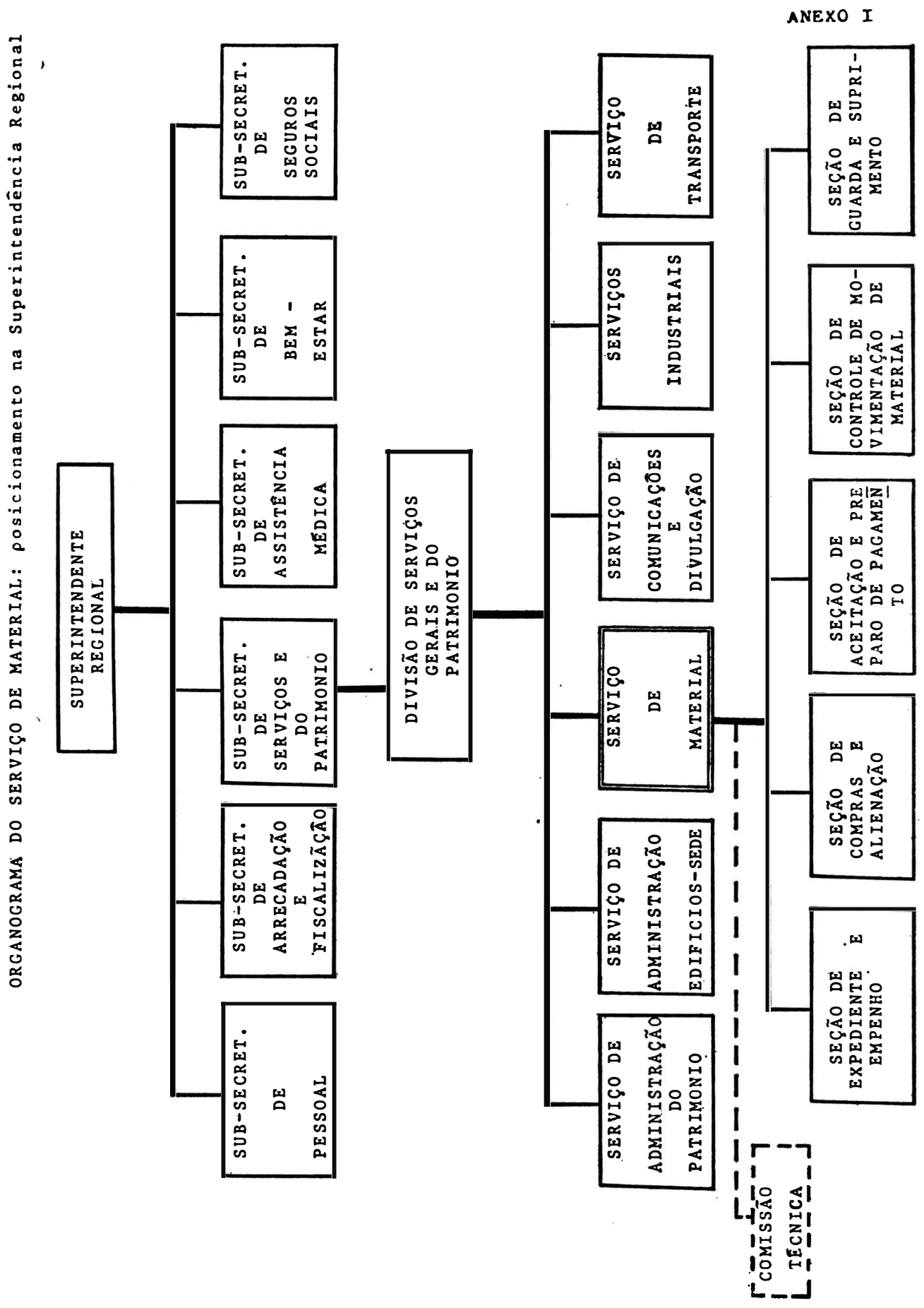

